\title{
Longitudinal analysis of protein glycosylation and $\beta$-casein phosphorylation in term and preterm human milk during the first 2 months of lactation
}

\author{
Claire E. Molinari ${ }^{1 *}$, Ylenia S. Casadio ${ }^{1}$, Ben T. Hartmann ${ }^{2}$, Peter G. Arthur ${ }^{1}$ and Peter E. Hartmann ${ }^{1}$ \\ ${ }^{1}$ School of Chemistry and Biochemistry, The University of Western Australia, M310, 35 Stirling Highway, \\ Crawley, WA 6009, Australia \\ ${ }^{2}$ Perron Rotary Express Milk Bank, Neonatology Clinical Care Unit, King Edward Memorial Hospital for Women, \\ 374 Bagot Road, Subiaco, WA 6008, Australia \\ (Submitted 22 February 2012 - Final revision received 3 August 2012 - Accepted 31 August 2012 - First published online 27 November 2012)
}

\section{Abstract}

Human milk proteins provide term and preterm infants with both nutrition and protection. The objective of the present study was to examine longitudinal changes in the protein composition of term and preterm milk during the first 2 months of lactation, focusing on protein phosphorylation and glycosylation. Using gel electrophoresis, the relative concentration and glycosylation status of lactoferrin, secretory Ig A, $\beta$-casein, $\alpha$-lactalbumin, serum albumin, bile salt-stimulated lipase, xanthine oxidoreductase, tenascin and macrophage mannose receptor 1 were measured in milk collected on days 7, 10, 14, 18, 21, 28 and 60 postpartum from preterm mothers (28-32 weeks gestation, $n$ 17). The phosphorylation status of $\beta$-casein was also investigated. To determine if these variables differ in term and preterm milk, samples from term mothers (38-41 weeks gestation, $n$ 8) collected on days 7, 14 and 30 of lactation were also analysed. The concentration of the abundant milk proteins decreased during lactation in term and preterm milk $(P<0.05)$. No difference in protein glycosylation was observed, except for the glycoproteins serum albumin and tenascin. The phosphorylation of $\beta$-casein varied significantly between term and preterm milk. Further investigation is required to determine whether these modifications affect protein function and are clinically important to preterm infants.

\section{Key words: Preterm milk: Macronutrient composition: Glycosylation: Phosphorylation}

Preterm infants experience significant benefits to their gastrointestinal maturation, neurodevelopmental outcome, host defence systems and nutritional status when fed their mother's own milk rather than infant formula ${ }^{(1)}$. The proteins present in human milk contribute to many of these beneficial effects, in particular by providing preterm infants with immunological protection and growth factors to aid in development ${ }^{(2)}$. Furthermore, clinical studies have found that the amount of total protein, the ratio of protein:energy and the amount of individual proteins such as lactoferrin (LF) delivered to preterm infants each have an effect on growth and development ${ }^{(3)}$.

Due to the importance of human milk proteins for the growth and development of preterm infants, a number of studies have investigated the protein composition of preterm milk ${ }^{(4)}$. Generally, these studies have focused on the concentration of the major proteins, recording any variation between mothers or throughout the course of lactation. Although there has been some inconsistency in the literature, higher levels of total protein and elevated concentrations of individual protective proteins in preterm milk have been reported by several authors in the early postpartum period ${ }^{(4-6)}$. A much higher level of compositional variation has also been found amongst preterm mothers compared with term mothers, particularly in the first 2 weeks of lactation ${ }^{(6)}$. It has been argued that these compositional differences between term and preterm milk arise due to the immaturity or unpreparedness of the mammary gland at the time of delivery, coupled with the presence of an altered hormonal milieu ${ }^{(4)}$

Despite a number of studies examining the concentration of proteins in preterm milk, the post-translational modification (PTM) of these proteins has largely been ignored. This is surprising given the profound effect that PTM can exert on protein functionality. For example, both protein glycosylation and phosphorylation have been found to be functionally important in human milk. The two milk proteins lactadherin and mucin are heavily glycosylated, and it is this modification that confers their ability to protect the infant against rotavirus and Escherichia coli, respectively ${ }^{(7,8)}$. In addition, glycosylation has been shown to be protective against proteolytic degradation ${ }^{(9)}$ and to modulate pathogen associations of milk proteins ${ }^{(10)}$

Abbreviations: ALA, $\alpha$-lactalbumin; BSSL, bile salt-stimulated lipase; LF, lactoferrin; MMR, macrophage mannose receptor; PTM, post-translational modification; SA, serum albumin; sIgA, secretory IgA; XOR, xanthine oxidoreductase.

*Corresponding author: C. E. Molinari, email 10224872@student.uwa.edu.au 
The phosphorylation of $\alpha_{\mathrm{s} 1}$-casein and $\beta$-casein in human milk is also of biological importance, in that this modification is critical to the formation of casein micelles and the subsequent delivery of $\mathrm{Ca}^{2+}$ and $\mathrm{PO}_{4}{ }^{3-}$ to the infant ${ }^{(11)}$. In addition, casein phosphopeptides, formed by the enzymatic digestion of intact casein after ingestion by the infant, have been shown to possess important biological functions, enhancing the bioavailability of $\mathrm{Ca}$ and other minerals ${ }^{(12)}$.

It is important that the PTM of proteins in preterm milk be further characterised. Given that post-translational protein modifications have an effect on the stability, structure and function of many bioactive milk proteins, assessing whether PTM varies between women and over the course of lactation will yield important information regarding the functionality of human milk for preterm infants. Investigating differences between term and preterm milk may also provide insights into the effect of premature delivery on protein synthesis in the mammary gland.

In the present study, we investigated the expression and PTM of proteins from preterm milk (28-32 weeks gestation) and term milk (38-41 weeks gestation) during the first 2 months of lactation. Previous studies have observed a higher degree of compositional variability, both between individuals and over the course of lactation, in preterm milk compared with term milk ${ }^{(4,5)}$. For this reason, the longitudinal profiles of preterm milk were investigated in greater detail, with more frequent sampling and a larger number of mothers analysed. The expression and glycosylation status of nine proteins were investigated: tenascin, macrophage mannose receptor (MMR), xanthine oxidoreductase (XOR), bile saltstimulated lipase (BSSL), LF, serum albumin (SA), secretory IgA (sIgA), $\beta$-casein and $\alpha$-lactalbumin (ALA). The phosphorylation of $\beta$-casein across the lactation period was also examined.

\section{Experimental methods}

\section{Chemicals}

Unless otherwise stated, all chemicals and reagents were obtained from Sigma-Aldrich.

\section{Sample collection}

Sample collection was carried out at the King Edward Memorial Hospital, Subiaco, Western Australia, and was approved by The University of Western Australia Human Research Ethics
Committee and the King Edward Memorial Hospital Ethics Committee. Written informed consent was obtained from all participating donors. Preterm milk samples were obtained from healthy mothers who delivered their infants between 28 and 32 weeks of gestation. On days 7, 10, 14, 18, 21, 28 and 60 postpartum, milk was expressed using a hospital-grade breast pump between 09.00 and 12.00 hours. The total expression volume was mixed together and a $2 \mathrm{ml}$ aliquot collected. Term milk samples were obtained from healthy mothers who delivered their infants between 38 and 41 weeks of gestation. Samples were collected on days 7, 14 and 30 postpartum using hand expression at the conclusion of a morning breastfeed (between 09.00 and 12.00 hours). Participant details are summarised in Table 1 . All mothers gave written informed consent to participate in the research, and had experienced their milk 'coming in' prior to the commencement of sample collection. All milk samples were frozen within $1 \mathrm{~h}$ of expression at $-20^{\circ} \mathrm{C}$, and transferred to $-80^{\circ} \mathrm{C}$ within $7 \mathrm{~d}$. Upon thawing each sample for analysis, a mammalian protease inhibitor cocktail containing 4-(2-aminoethyl)benzenesulfonyl fluoride, E-64, bestatin, leupeptin, aprotinin and sodium EDTA was added.

\section{Casein separation}

Casein was collected from skimmed milk samples, as previously described ${ }^{(13)}$. Briefly, milk samples $(500 \mu \mathrm{l})$ were removed from storage at $-80^{\circ} \mathrm{C}$ and placed in an ice bath prior to a $\mathrm{pH}$ adjustment to $4 \cdot 3$. After $1 \mathrm{~h}$, the acidified milk samples were diluted in the ratio $1: 1$ with $120 \mathrm{~mm}-\mathrm{CaCl}_{2}$ and vortexed gently for $20 \mathrm{~min}$. Samples were then centrifuged at $40000 \mathrm{~g}$ for $1 \mathrm{~h}$ at $4^{\circ} \mathrm{C}$, and the fat, whey and casein collected separately. The casein pellets were washed in $1 \mathrm{ml}$ water, centrifuged again and resuspended in $8 \mathrm{M}$-urea and $4 \%$ 3-[(3-cholamidopropyl) dimethylammonio]-1-propanesulfonate (CHAPS) ( $\mathrm{pH} \mathrm{8.5).}$

\section{Protein determination}

The concentration of true protein, excluding non-protein $\mathrm{N}$, was determined as previously described ${ }^{(14)}$ using a modified Bradford method and a commercial protein reagent (Bio-Rad Laboratories), with human milk standards used to calibrate the measurements. The recovery of a known amount of protein added to the milk samples was 99 (SEM 1.03 ) \% ( $n$ 12), the interassay CV was $5.0 \%$ and the detection limit was $0 \cdot 015 \mathrm{~g} / 1$.

Table 1. Details of the study population

(Medians and ranges)

\begin{tabular}{|c|c|c|c|c|}
\hline \multirow[b]{2}{*}{ Participant details } & \multicolumn{2}{|c|}{ Preterm mothers } & \multicolumn{2}{|c|}{ Term mothers } \\
\hline & Median & Range & Median & Range \\
\hline Number of participants $(n)$ & \multicolumn{2}{|c|}{17} & \multicolumn{2}{|c|}{8} \\
\hline Maternal age (years) & 32 & $18-43$ & 33 & $25-38$ \\
\hline Gestational age at delivery (d) & 215 & $196-224$ & 275 & $268-287$ \\
\hline Infant weight at delivery (g) & 1317 & $825-2370$ & 3345 & $2732-4420$ \\
\hline Primiparity $(n)$ & \multicolumn{2}{|c|}{15} & \multicolumn{2}{|r|}{ - } \\
\hline Day of first sample collection & 10 & $7-14$ & & \\
\hline
\end{tabular}




\section{Lactose determination}

The lactose content of milk was determined by an enzymatic spectroscopic method $^{(14)}$. The recovery of a known amount of lactose added to the milk samples was 101 (SE 0.9)\% ( $n$ 12). The detection limit of this assay was $0 \cdot 17 \mathrm{~g} / 1(n$ 16) and the inter-assay CV was $3.5 \%$ ( $n$ 60).

\section{SDS-PAGE}

The skimmed milk protein analysis and analysis of casein profiles were conducted using the HOEFER gel apparatus (HOEFER Scientific Instruments) with the Laemmli gel system $^{(15)}$. All samples were run in duplicate on $12.5 \%$ polyacrylamide gels using a constant current of $9 \mathrm{~mA}$ for $16 \mathrm{~h}$ at $4^{\circ} \mathrm{C}$. For the analysis of skimmed milk proteins, $20 \mu \mathrm{g}$ of protein was loaded. Gels were fixed, stained using Coomassie Blue Silver and scanned as described previously ${ }^{(16)}$.

The glycoprotein analysis was conducted using the Bio-Rad Mini-Protean tetra cell apparatus (Bio-Rad Laboratories) and the Laemmli gel system. A measure of $3 \mu \mathrm{g}$ of skimmed milk protein samples was loaded onto precast 4-20\% gradient polyacrylamide gels (TGX precast gels; Bio-Rad Laboratories). Gels were run at a constant voltage of $200 \mathrm{~V}$ for $40 \mathrm{~min}$. Gels were stained for glycoproteins using a Pro-Q ${ }^{\circledR}$ Emerald Glycoprotein Gel and Blot Stain Kit (Invitrogen) according to the manufacturer's instructions. Glycoproteins were imaged using a ChemiDoc XRS System (Bio-Rad Laboratories). Gels were then stained using Coomassie Blue Silver, as described earlier, in order to observe the total protein content.

\section{Urea-PAGE}

One-dimensional urea-PAGE was conducted according to Kinoshita et al. ${ }^{(17)}$ using the Bio-Rad Mini-Protean tetra cell. Briefly, gels consisted of a stacking gel ( $4.0 \%$ polyacrylamide $(\mathrm{w} / \mathrm{v}), 125 \mathrm{~mm}-\mathrm{Tris}-\mathrm{HCl}(\mathrm{pH}$ 6.8) and $4.0 \mathrm{M}$-urea) and a separating gel $(6.0 \%$ polyacrylamide $(\mathrm{w} / \mathrm{v}), 375 \mathrm{~mm}-\mathrm{Tris}-\mathrm{HCl}$ ( $\mathrm{pH} 8.8$ ) and 4.0 M-urea). The electrophoresis running buffer ( $\mathrm{pH} \mathrm{8.4)} \mathrm{was} 25 \mathrm{~mm}$-Tris and $192 \mathrm{~mm}$-glycine. Samples were mixed with a loading buffer containing $250 \mathrm{~mm}-$ Tris- $\mathrm{HCl}$ ( $\mathrm{pH}$ 6.8), 4.0 M-urea, 5.0\% glycerol, $2.5 \%$ dithiothreitol (w/v) and $0 \cdot 1 \%$ bromophenol blue $(\mathrm{w} / \mathrm{v})$.

Gels were run at $20 \mathrm{~mA} / \mathrm{gel}$. A measure of $10 \mu \mathrm{g}$ of each casein fraction was loaded into individual wells. Each sample was analysed in duplicate. Gels were run at a constant current of $20 \mathrm{~mA}$ for $150 \mathrm{~min}$, fixed, stained using Coomassie Blue Silver and scanned in the same manner described earlier for the skimmed milk samples.

As an experimental control, dephosphorylated casein was prepared by incubating a solution containing $5 \mathrm{mg}$ casein, $50 \mathrm{~mm}$-Tris- $\mathrm{HCl}\left(\mathrm{pH} \mathrm{9.0)}\right.$ and $1.0 \mathrm{~mm}-\mathrm{MgCl}_{2}$ with $2 \mathrm{nmol} / \mathrm{min}$ ( $2 \mathrm{mU}$ ) of bovine intestinal mucosa alkaline phosphatase at $37^{\circ} \mathrm{C}$. After $6 \mathrm{~h}$, the reaction was stopped by adding an equal volume of urea-PAGE loading buffer.

\section{Gel analysis}

Gels were analysed using the open access software package ImageJ 1.410 (National Institutes of Health; http://imagej.nih.gov/ij/).
All gels were run in duplicate, and all measurements of band intensity were also conducted in duplicate. All quantitative comparisons were made using background-subtracted integrals of either Coomassie or Pro-Q Emerald electrophoretic peaks. The average CV between repeat intensity measurements of the same protein band was $2 \cdot 7 \%$ ( $n$ 200). The within-gel loading variability, given by the average CV of the total lane intensities, was $6.4 \%$ ( $n$ 40). The between-gel variability, given by the average $\mathrm{CV}$ of the relative intensities of duplicate samples on different gels, was 8.4\% ( $n$ 209). Different gel analysis protocols were used for the analysis of protein expression and glycoprotein expression, as described later.

\section{Analysis of protein expression}

The percentage quantity of each protein band was calculated by measuring the band intensity and normalising it against the total intensity of each lane. By multiplying this value by the total protein concentration, the relative concentration of each protein was calculated. No protein standards were used to provide absolute quantitation from the gel analysis, and thus all measures are relative only.

\section{Glycoprotein analysis}

The intensity of each band was measured and normalised against the total amount of protein present in each lane (Coomassie Blue Silver stain). The intensity of the glycoprotein molecular weight marker on each gel was used to correct for gel-to-gel differences in staining efficiency. In order to assess whether the glycan content varied relative to the amount of protein present, the normalised intensity of each glycoprotein was divided by the percentage quantity of the corresponding protein (calculated as given earlier for the Coomassie-stained protein bands) and expressed as a unitless ratio.

\section{MS}

Bands and spots of interest were cut from the gel, destained and digested in gel with trypsin (Roche Diagnostics), as described by Shevchenko et al. ${ }^{(18)}$. MS analysis was conducted as described in a previous study ${ }^{(16)}$

MS/MS data were imported into the database search engine (Mascot, version 2.3.01; www.matrixscience.com). Mascot searches were conducted using the SwissProt Mammalia database (49887 sequences) with the following settings: number of missed cleavages permitted $=1$; no fixed modifications; variable modifications $=$ methionine oxidation, cysteine carbamidomethylation; peptide tolerance $=1 \cdot 2 \mathrm{Da}, \mathrm{MS} / \mathrm{MS}$ tolerance $=$ $0.6 \mathrm{Da} ;$ enzyme $=$ trypsin; and the peptide charge $=+1$. A Mascot score greater than 50 , with a minimum of two peptide matches, was considered to be a significant identification.

\section{Statistical analysis}

Statistical analysis was carried out using the statistics package $\mathrm{R}^{(19)}$. The packages nlme ${ }^{(20)}$ and multcomp ${ }^{(21)}$ were used for 
linear mixed effects modelling and Tukey's contrast analysis, respectively.

Univariate analysis for variables collected at multiple time points was performed using a linear mixed models approach. This method is considered appropriate given the variation between different milk samples and the repeated measures in the data. All models included the individual milk samples as the grouping. ANOVA of the fitted model objects found that a grouping variable of the duplicate gels within the data from each milk sample did not improve the models. The mean concentrations of each milk component were compared, both within and between mothers, using general linear hypothesis tests.

Values are presented as means and standard deviations unless otherwise specified. $P$ values $<0.05$ were considered statistically significant and values smaller than 0.001 have been reported as $P<0 \cdot 001$.

\section{Results \\ Macronutrient concentration}

The total protein concentration decreased across the first 2 months of lactation in both term and preterm mothers, with no difference observed between term and preterm milk on days 7, 14 and 30 (Fig. 1(a)). In term milk, the protein concentration was highest on day 7 at $17 \cdot 9$ (SD 2.2) g/l and decreased during lactation, with the protein concentrations on days 14 $(P=0.041)$ and $30(P<0.001)$ both significantly lower than the concentration on day 7 . In preterm milk, the concentration was highest on day 7 at $19 \cdot 3$ (SD 5.5) g/l and remained elevated across the second week, falling only slightly to 17.5 (SD $4.5) \mathrm{g} / \mathrm{l}$ by day 14 . The protein concentrations on days 14,18 , 21,28 and 60 of lactation were all significantly lower than the concentration on day $7(P=0.032,<0.001,<0.001,<0.001$ and $<0 \cdot 001$, respectively).

The lactose concentration changed minimally across the first 2 months of lactation in the preterm milk samples (Fig. 1(b)). The lactose concentration on day 7 was 55.3 (SD 8.8) g/l. The concentration remained steady at this level, with concentrations of 54.5 (SD 2.9) g/l and 55.7 (SD 3.8) g/l at days 28 and 60 , respectively. In term milk, the lactose concentration was constant at $55(\mathrm{SD} 7 \cdot 0) \mathrm{g} / \mathrm{l}$ on day 7 and remained constant thereafter. No difference was found between the concentration of lactose in term and preterm milk.

\section{Protein profiles}

Each milk sample was analysed using SDS-PAGE in order to identify changes in the protein profile over the course of lactation in term and preterm milk. The identity of nine major proteins was determined using matrix-assisted laser desorption/ionisation time-of-flight-time-of-flight MS (MALDITOF-TOF MS) (Table 2). In term milk, the concentration of tenascin (Fig. 1(c)), XOR (Fig. 1(e)), LF (Fig. 1(g)), SIgA (Fig. 1(i)), $\beta$-casein (Fig. 1(j), (k)) and ALA (Fig. 1(1)) decreased during lactation, with the concentration on day 30 being significantly lower than that on day $7(P<0.05$ for all comparisons). No change in concentration over time was observed for MMR, SA and BSSL in term milk.

Similar longitudinal patterns were observed in preterm milk. The concentrations of tenascin (Fig. 1(c)), LF (Fig. 1(g)) and sIgA (Fig. 1(i)) were highest on day 7 and decreased over time, with the concentration on days 14, 18, 21, 28 and 60 all being significantly lower to that on both days 7 and 10 (all pairwise comparisons $P<0.05$ ). Similarly, the concentration of ALA also decreased significantly after day 7 in preterm milk (Fig. 1(1)), with the concentration of ALA on days 18, 21, 28 and 60 all being lower than that on day 7 (all pairwise comparisons $P<0 \cdot 05$ ). The two $\beta$-casein bands (28 and $16 \mathrm{kDa}$ ) displayed slightly different profiles to each other, although both also decreased in concentration over time. For the $28 \mathrm{kDa} \beta$-casein band (Fig. 1(j)), the concentration on days 28 and 60 were both lower to the concentration on each of the days $7,10,14,18$ and 21. This was the same pattern of difference observed for BSSL (Fig. 1(f)). For the $16 \mathrm{kDa}$ $\beta$-casein band (Fig. 1(k)), the concentration decreased more noticeably over time, with the concentration on each subsequent time point being lower compared with that on day 7 (all pairwise comparisons $P<0.05$ ). No significant difference was observed during the 60-d period in preterm milk for SA (Fig. 1(h)). Both MMR (Fig. 1(d)) and XOR (Fig. 1(e)) showed only a slight decrease in concentration over time, with the concentration on day 60 being lower than that on days 10, 14 and 21 (all pairwise comparisons $P<0.05$ ).

Comparing term and preterm milk, no difference was found for the concentration of MMR, LF, SA, SIgA, $\beta$-casein or ALA. However, differences were found between term and preterm milk for the concentration of tenascin, XOR and BSSL. The concentration of tenascin in term milk was higher on days 7 , 14 and $30(P<0.05)$ compared with preterm milk (Fig. 1(c)). XOR was present at a higher concentration in term milk on day $7(P=0.02)$, but was similar on days 14 and 30 (Fig. 1(e)). BSSL had a similar concentration in term and preterm milk on days 7 and 30 of lactation, but was lower in term milk on day $14(P<0 \cdot 001)$ (Fig. 1(f)).

\section{Glycosylation status of individual proteins}

ProQ Emerald Stain 300 was used to detect glycoproteins on SDS-PAGE gels. A number of proteins, including tenascin, MMR, BSSL, LF, SA, SIgA and ALA, were identified as glycoproteins, exhibiting differing levels of glycosylation. The concentration of each of these glycoproteins varied over the first $60 \mathrm{~d}$ of lactation. However, when expressed relative to the concentration of the respective proteins, the glycan content of MMR (Fig. 2(b)), BSSL (Fig. 2(c)), LF (Fig. 2(d)), SIgA (Fig. 2(f)) and ALA (Fig. 2(g)) was found to be constant during the $60 \mathrm{~d}$ period in both term and preterm mothers. For tenascin (Fig. 2(a)) and SA (Fig. 2(e)), the extent of protein glycosylation was found to differ throughout lactation in term and preterm mothers.

No change in the extent of tenascin glycosylation was observed during lactation in the term population, whereas in the preterm population, two distinct patterns were observed, with the level of glycosylation either remaining constant or 
(a)

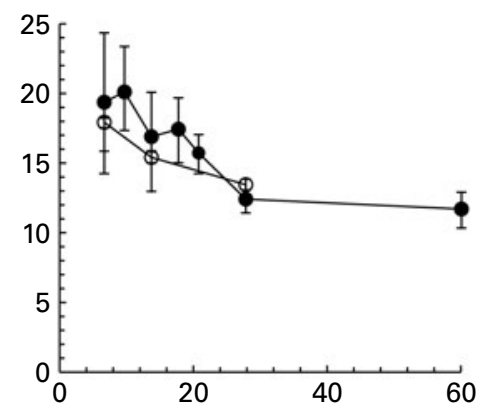

(d)

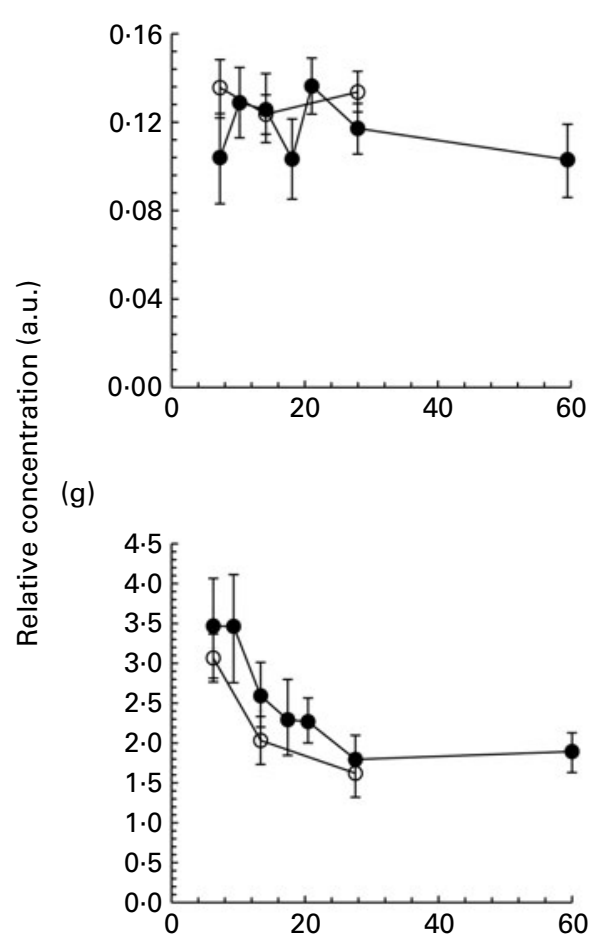

(j)

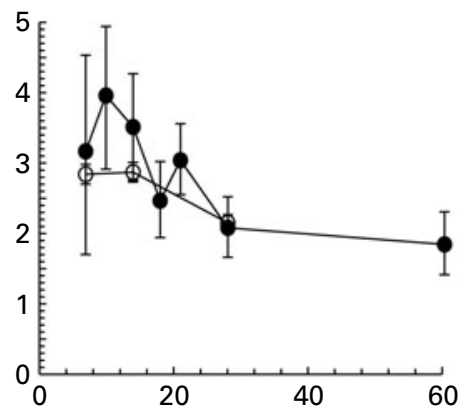

(b)

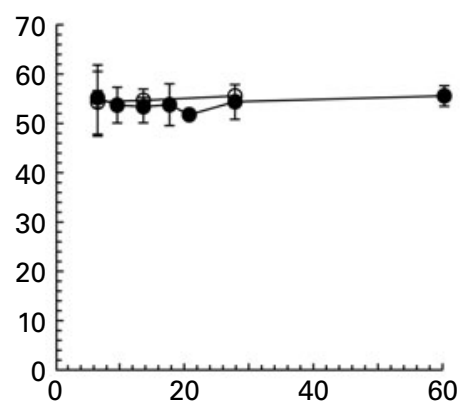

(e)

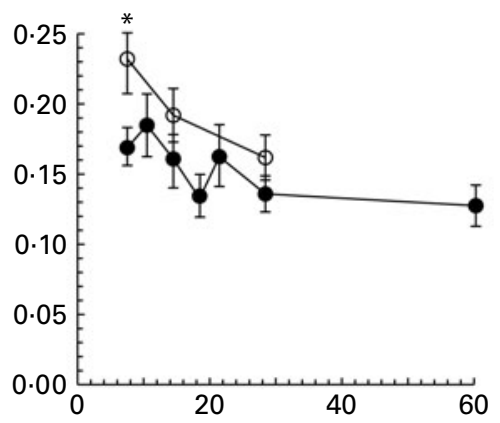

(h)

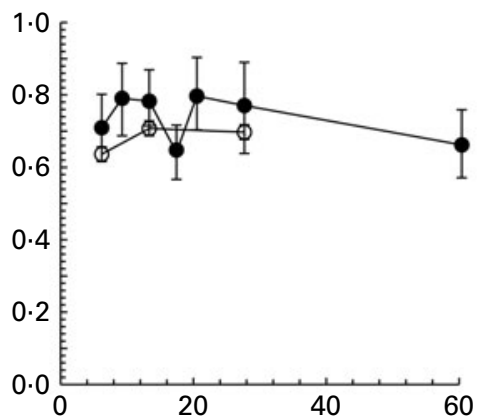

(k)

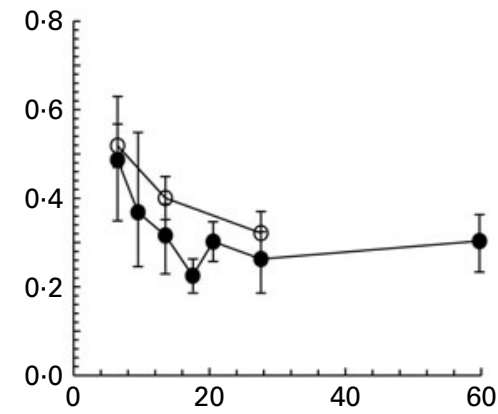

Stage of lactation (days postpartum) (c)

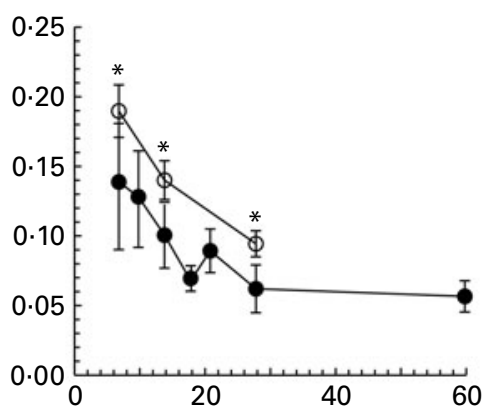

(f)

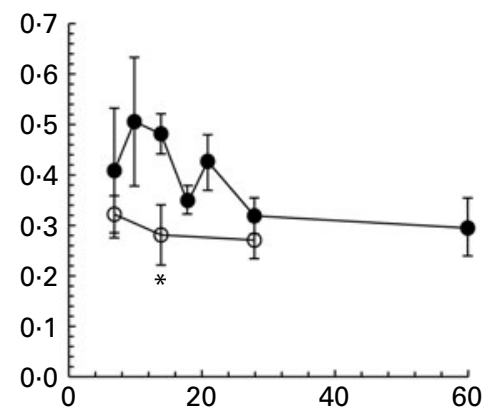

(i)

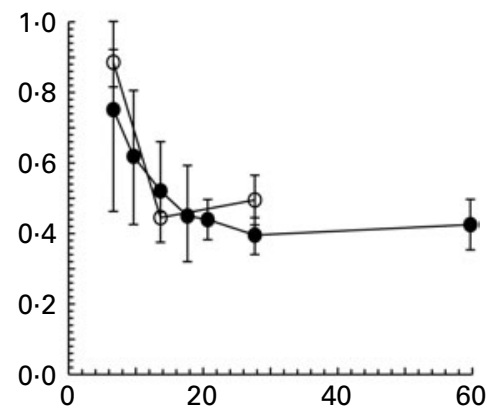

(I)

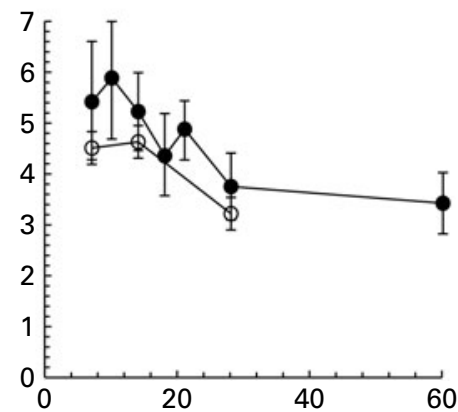

Fig. 1. The concentration of (a) protein (g/l), (b) lactose (g/l), (c) tenascin (arbitrary units (a.u.)), (d) macrophage mannose receptor (a.u.), (e) xanthine oxidoreductase (a.u.), (f) bile salt-stimulated lipase (a.u.), (g) lactoferrin (a.u.), (h) serum albumin (a.u.), (i) secretory lg A (a.u.), (j) $28 \mathrm{kDa} \beta$-casein, (k) $16 \mathrm{kDa} \beta$-casein and (I) $\alpha$-lactalbumin (a.u.) in preterm milk $(\bullet)$ and term milk $(O)$ during $60 \mathrm{~d}$ of lactation, expressed in a.u. Values are means and standard deviations represented by vertical bars. * Time points with a significantly different concentration $(P<0.05)$ in term and preterm milk. 
Table 2. Protein identifications

\begin{tabular}{llccr}
\hline Protein name & Uniprot ID & $\begin{array}{c}\text { Molecular weight } \\
\text { off gel (kDa) }\end{array}$ & $\begin{array}{c}\text { Number of } \\
\text { peptides }\end{array}$ & Mascot score \\
\hline Tenascin & P24821 & 260 & 4 & 82 \\
Fatty acid synthase & P49327 & 250 & 3 & 40 \\
Macrophage mannose receptor 1 & P22897 & 165 & 2 & 70 \\
Xanthine oxidoreductase & P47989 & 148 & 6 & 148 \\
Bile salt-stimulated lipase & P19835 & 85 & 2 & 88 \\
Lactoferrin & P02788 & 80 & 7 & 296 \\
Serum albumin & P02768 & 65 & 2 & 56 \\
Secretory Ig A & P01876 & 60 & 2 & 135 \\
$\beta$-Casein & P05814 & 28 & 2 & 95 \\
$\beta$-Casein & P05814 & 16 & 2 & 88 \\
$\alpha$-Lactalbumin & P00709 & 15 & & 2 \\
\hline
\end{tabular}

decreasing over lactation for individual mothers. For the analysis of tenascin glycosylation, mothers were grouped according to these patterns (Fig. 2(a)). The level of glycosylation was constant during lactation for ten of the preterm mothers. For the remaining seven mothers, the level of glycosylation decreased markedly across the $60 \mathrm{~d}$ of lactation, with the ratio of carbohydrate:protein being higher at day 7 than at days 21, 28 and 60 ( $P=0.041,0.004$ and 0.002, respectively). For these seven mothers, the level of glycosylation was significantly different compared with the term population on both days $7(P<0.001)$ and $28(P=0.02)$. There was no significant difference between the two groups of preterm mothers for any of the other variables measured.

The glycosylation of SA (Fig. 2(e)) in preterm milk also displayed changes across the first $60 \mathrm{~d}$ of lactation. The ratios of carbohydrate:protein on days 21 and 28 were both lower than those on days $7(P=0.006,0.011)$ and $10(P=0.007,0.014)$, respectively. In term milk, no change in the level of glycosylation was observed during lactation. A significant difference was found between the glycan content of SA in term and preterm milk on day $7(P=0.03)$, with a higher degree of glycosylation observed in the preterm milk.

\section{Casein phosphorylation}

Urea-PAGE was used to separate the differentially phosphorylated forms of $\beta$-casein in term and preterm milk. Six distinct bands were visible in the electrophoretograms, corresponding to $\beta$-casein with $0,1,2,3,4$ and 5 attached phosphate groups, respectively (Fig. 3(a)). These assignments were made based on a range of evidence. Using MALDI-TOF-TOF MS, each band was identified as $\beta$-casein, with the same two peptides identified in each band: $m / z$ 1468.8 (residues 120-132, SPTIPFFDPQIPK) and $m / z \quad 1633.9$ (residues 176-189, VLPIPQQVVPYPQR). No phosphorylated peptides were detected, so it was not possible to assign bands to particular forms of casein. The dephosphorylated form of $\beta$-casein was identified using alkaline phosphatase to create a sample of dephosphorylated casein (Fig. 3(a)). The corresponding forms of the multiple-phosphorylated proteins were then assigned to the protein bands based on the description given by Kinoshita et al. $^{(17)}$.

The casein phosphorylation patterns present in preterm skimmed milk varied both between and within mothers
(Fig. 3), with marked differences between term and preterm milk. Four different longitudinal patterns were observed. In term milk, the level of phosphorylation decreased over time in milk from seven of the eight mothers analysed (Fig. 3(d)). In preterm milk, the level of phosphorylation increased over the course of lactation in six of the sixteen samples analysed (Fig. 3(b)). In the remaining ten mothers, no change in phosphorylation pattern was observed over time. For six of these mothers, $\beta$-casein was present in five phosphorylated casein isoforms of relatively even intensity (Fig. 3(e)). This pattern was also observed in one of the term mothers. For the remaining four preterm mothers, only three phosphorylated casein isoforms were visible, with the band representing casein with four attached phosphate groups being significantly more intensely stained compared with the others (Fig. 3(c)).

\section{Discussion}

In the present study, the protein composition of term (38-41 weeks gestation) and preterm (28-32 weeks gestation) milk over the first 2 months of lactation was investigated. One of the strengths of the present study is that the relative concentration and PTM of a large number of proteins were measured simultaneously in the same set of milk samples, enabling relationships between them to be examined. The concentration, glycosylation and phosphorylation of the major proteins in human milk were found to vary over the course of lactation. Differences between term and preterm milk were found for the glycosylation of tenascin and SA and for the phosphorylation of $\beta$-casein. This is the first time that longitudinal changes in these protein modifications have been reported in human milk samples.

We used a gel-based assay to measure the relative concentration of nine of the most abundant proteins in human milk, namely tenascin, MMR, XOR, BSSL, LF, SA, sIgA, $\beta$-casein (28 and $16 \mathrm{kDa}$ isoforms) and ALA, together with the concentration of total protein and lactose. With the exception of MMR, each of the individual proteins and the concentration of total protein decreased throughout the first $60 \mathrm{~d}$ of lactation in both term and preterm mothers (Fig. 1). Protein expression was similar in term and preterm milk, except for the proteins tenascin and XOR, which had a higher concentration in term milk on days 7 and 14 of lactation. Whilst many other studies have found higher concentrations of total protein, LF and SIgA 
(a) 120

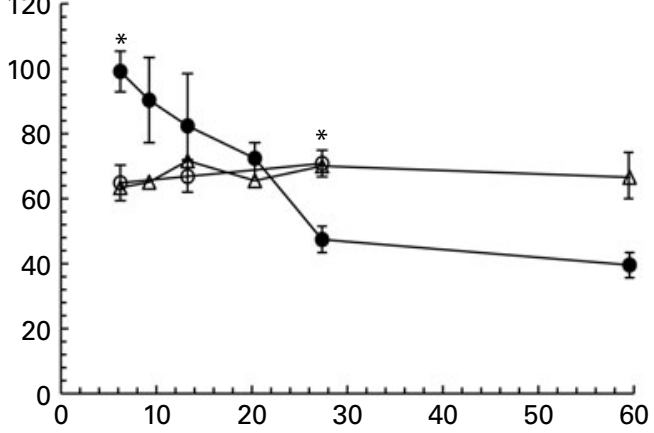

(c)

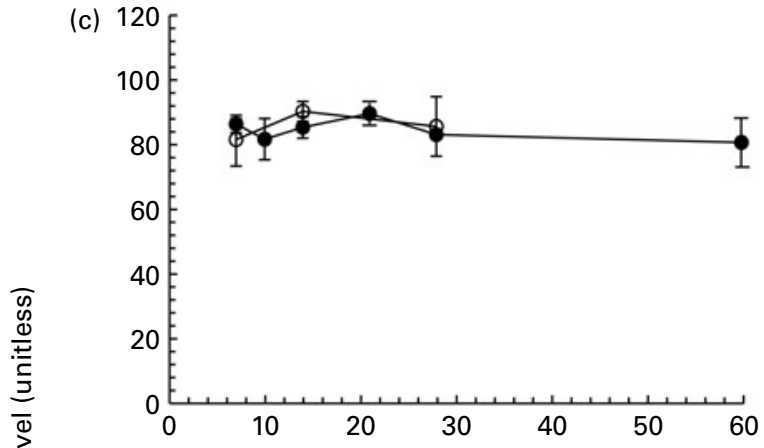

(e) 120

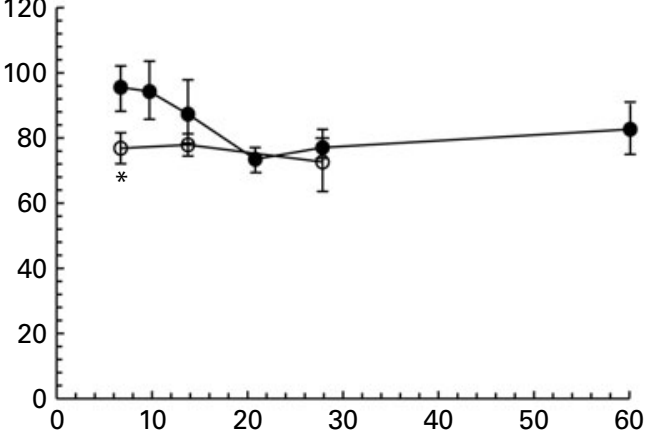

(b)

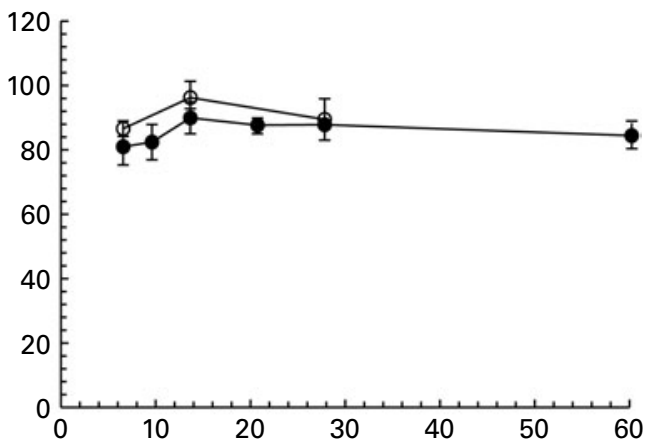

(d) 120

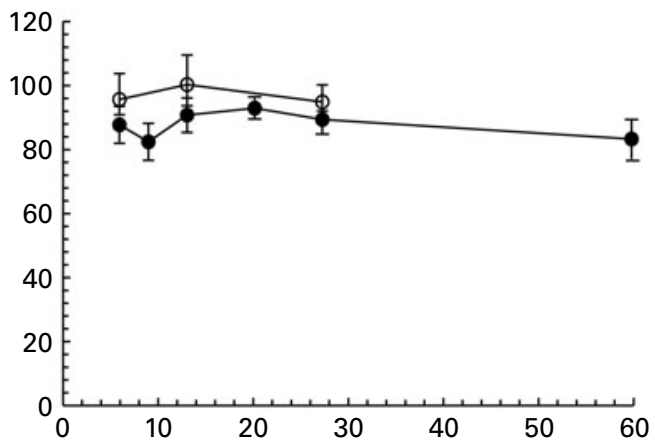

(f)

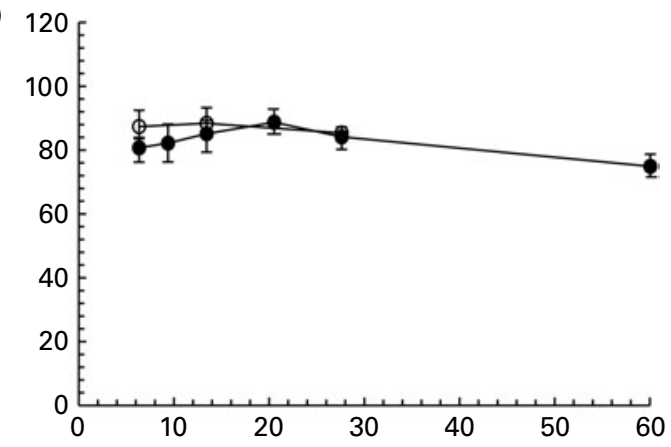

(g) 120

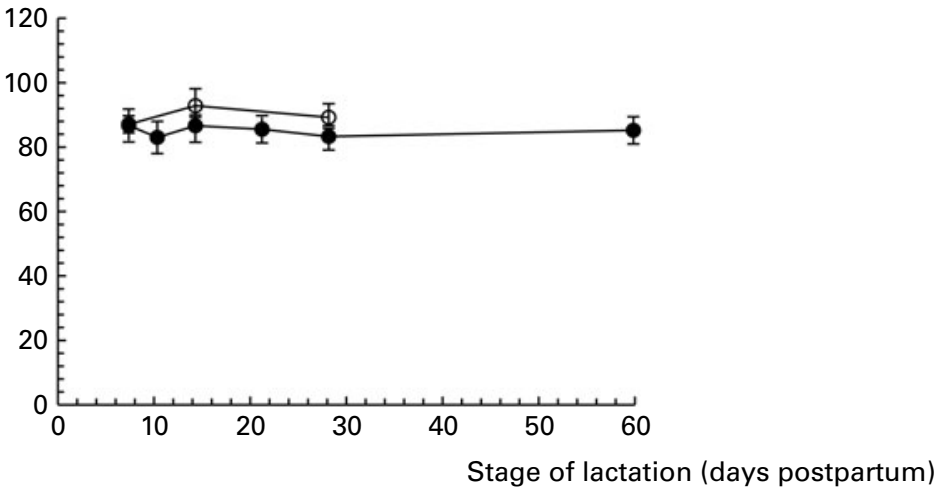

Fig. 2. The level of protein glycosylation during the first $60 \mathrm{~d}$ of lactation in milk from term (T, $n 8$ ) and preterm (PT, $n$ 17) mothers. (a) Tenascin (O, $n 8 \mathrm{~T} ; \bullet, n 7 \mathrm{PT}$;

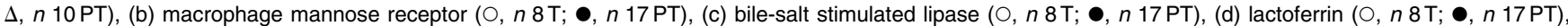
(e) serum albumin $(\mathrm{O}, n 8 \mathrm{~T} ; \bullet, n 17 \mathrm{PT})$, (f) secretory $\lg \mathrm{A}(\mathrm{O}, n 8 \mathrm{~T} ; \bullet, n 17 \mathrm{PT})$ and $(\mathrm{g}) \alpha$-lactalbumin $(\mathrm{O}, n 8 \mathrm{~T} ; \bullet, n 17 \mathrm{PT})$. Values (unitless) are expressed as the ratio of ProQ Emerald stain (glycosylation) to Coomassie Blue Silver stain (protein expression) for individual protein bands. Two distinct patterns were observed for the glycosylation of tenascin amongst the preterm mother cohort, and are thus shown separately in (a). For all other protein bands, all term and preterm mothers are grouped together. Values are means and standard deviations represented by vertical bars. * Significant differences $(P<0.05)$ between term and preterm milk. 

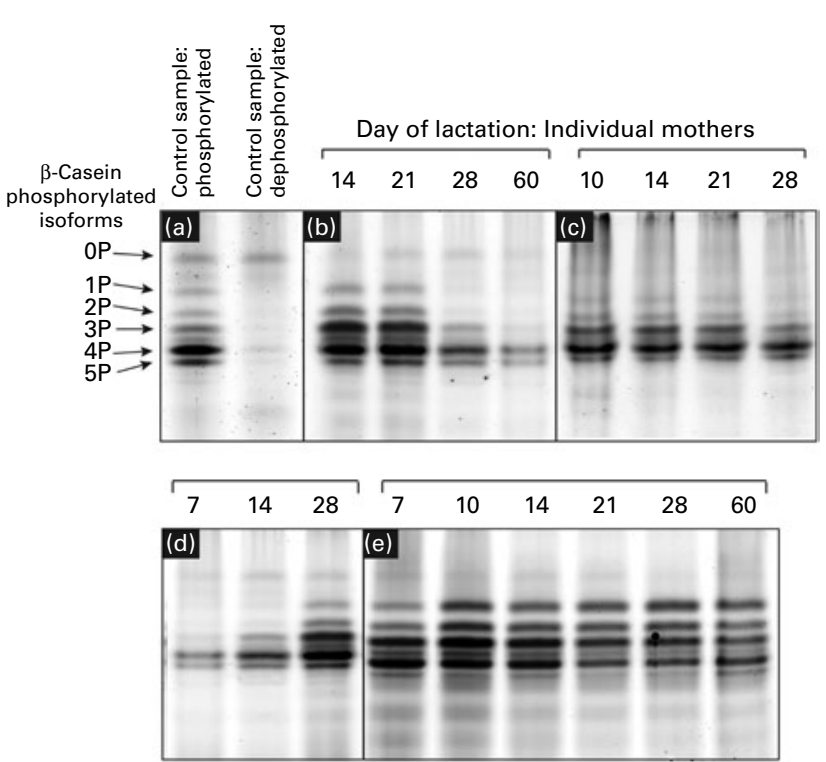

Fig. 3. Patterns of casein phosphorylation in human milk over the first 2 months of lactation in term $(n 8)$ and preterm mothers $(n$ 16). A pooled control sample of casein was dephosphorylated by incubation with alkaline phosphatase. (a) The casein samples after and prior to dephosphorylation are depicted. There was considerable variation between the longitudinal patterns of casein phosphorylation between individual mothers, with four basic patterns observed: (b) increase in phosphorylation, (c) no change, highly phosphorylated, (d) decrease in phosphorylation and (e) no change, less phosphorylation.

in preterm milk compared with term milk, these differences tend to be highest in the first few days postpartum ${ }^{(4,22)}$. In the present study, samples were not collected until $7 \mathrm{~d}$ postpartum, which may account for why differences between term and preterm milk were not observed.

It is to be noted that between days 7 and 60 postpartum in milk from preterm mothers, the concentrations of total protein, the immunological proteins LF and $\operatorname{sigA}$ and the nutritional protein ALA all fell by over $40 \%$. Given the significance of these proteins to preterm infant growth and development ${ }^{(23)}$, it is important that this change in protein concentration be taken into account when feeding human milk to preterm infants. In a hospital setting, preterm infants can receive human milk either from their own mother (often expressed on an earlier occasion and frozen for storage) or milk from a donor mother at a later stage of lactation. This milk is then routinely fortified with additional protein, energy and minerals in order to meet the high nutritional demands of preterm infants ${ }^{(24)}$. Using this standard protocol, it is possible that widely different quantities of total protein, as well as of individual bioactive proteins, will be delivered to preterm infants. Indeed, studies that have implemented adjustable fortification regimes to ensure that infants receive the appropriate level of protein and energy have observed improved infant outcomes ${ }^{(3,25)}$. The results of the present study support the rationale of these adjustable approaches.

In addition to mapping the longitudinal changes in protein expression in preterm mothers, we investigated the PTM of these proteins and found the majority of the abundant proteins in preterm milk to be glycosylated (Fig. 2(b)).
Glycosylation is an important protein modification in human milk, and has been shown to have profound effects on both the protection of infants from pathogens and infant development ${ }^{(26,27)}$. Whereas both tenascin and SA showed changes in the extent of glycosylation during lactation and between-term and preterm mothers, the degree of glycosylation of LF, MMR, BSSL, sIgA and ALA was constant during the first $60 \mathrm{~d}$ of lactation (Fig. 2). These results conflict with previous studies conducted in term milk, which reported BSSL, XOR, $\kappa$-casein and LF to be differentially glycosylated over the same time period ${ }^{(28-30)}$. It is possible that this disparity is due to differences in the number of milk samples analysed in each study. The previous studies in term milk observed the differential glycosylation during lactation of XOR and LF in only one mother ${ }^{(28)}$ and of BSSL in four mothers ${ }^{(29)}$, whereas the present study is based on a cohort of seventeen preterm mothers and eight term mothers. It also needs to be acknowledged that, although we did not find any changes in the extent of glycosylation of MMR, BSSL, SIgA, LF or ALA during lactation, this does not preclude the possibility of there being significant changes in the nature of the carbohydrates attached to the protein. Certainly, changes in the composition of protein glycans and milk oligosaccharides have been reported, both between women and throughout lactation $^{(10,29,31)}$, and it is likely that this was also the case in the present study.

We did observe a difference in protein glycosylation between term and preterm mothers for the protein tenascin. In term milk, no change in the level of glycosylation was observed during lactation. This was similar to the pattern observed in ten of the preterm mothers. However, for the remaining seven preterm mothers, the amount of bound carbohydrate per unit protein fell significantly over the first $60 \mathrm{~d}$ of lactation (Fig. 2(a)). Whilst its precise role in the mammary gland and human milk is unclear, there are indications that the heavily glycosylated extracellular protein tenascin is involved in the extensive tissue remodelling associated with both the periods of pregnancy and involution, acting to suppress the expression of milk-specific proteins during these times ${ }^{(32-34)}$. The functionality of tenascin is based on its adhesion to other components of the extracellular matrix and to cell surface receptors, and thus glycosylation, which alters its surface structure and adhesive properties, is critical to its function. The differential glycosylation of tenascin observed in the subset of preterm mothers during lactation, and compared with the term mothers, certainly warrants further investigation. Given the difference between term and preterm milk, and the probable roles of tenascin in the remodelling of the mammary gland and the suppression of milk proteins, it is possible that the different patterns of tenascin glycosylation observed are related to the developmental state of the mammary gland or to patterns of protein expression. Further investigation with a much larger sample set is needed to assess these possibilities.

Serum albumin was also found to be differentially glycosylated during lactation in preterm milk, although unlike tenascin, a consistent pattern was observed amongst each of the mothers (Fig. 2(e)). The level of glycosylation decreased during lactation and was higher compared with term milk at day 7 (Fig. 2(e)). Serum albumin is an abundant protein in 
human milk that enters milk from the bloodstream rather than being synthesised in the mammary gland ${ }^{(35)}$. It is known to bind to a number of different ligands in milk, potentially acting as a passive carrier ${ }^{(36)}$. It is not normally considered to be a major glycoprotein in milk, and indeed was not found to be glycosylated at all in a select group of term mothers ${ }^{(28)}$. However, serum albumin has been found in plasma to be non-enzymatically glycosylated (glycated) on a number of different sites ${ }^{(37)}$. Interestingly, the level of serum albumin glycation has been used as a marker of oxidative stress, with higher levels of glycation observed during disease states such as diabetes ${ }^{(38)}$. As serum albumin enters the milk from the bloodstream, it may be possible to view its glycation status as a reflection of the glycation experienced by the circulating serum albumin. Alternatively, the albumin may become glycated after entering the milk space, instead reflecting the oxidative status of milk. Indeed, preterm delivery has been associated with both higher levels of systemic oxidative stress $^{(39)}$ and with lower levels of antioxidants present in human milk ${ }^{(40)}$, potentially accounting for the higher level of serum albumin glycation observed in preterm milk. The observed fall in the glycation of serum albumin throughout lactation in preterm mothers (Fig. 2(e)) may, therefore, reflect either decreasing levels of maternal oxidative stress as lactation progresses or a change in the oxidative balance in milk itself. Whilst the glycation of serum albumin has been shown to have an effect on protein function ${ }^{(41)}$, it is unclear whether it has any effect on its role in human milk.

In addition to investigating the glycosylation of human milk proteins in term and preterm milk, we also examined the longitudinal patterns of $\beta$-casein phosphorylation. A longitudinal trend was observed amongst the term population, with the phosphorylation state of $\beta$-casein decreasing during lactation in seven of the eight mothers analysed (Fig. 3). In the preterm population, no change in the distribution of phosphorylated isoforms was observed over time in ten of the sixteen mothers, whereas in the other six mothers, the level of phosphorylation increased during lactation (Fig. 3). This is the most comprehensive report of longitudinal changes in $\beta$-casein phosphorylation in either term or preterm mothers, with previous studies reporting differences between samples collected from two to four mothers only ${ }^{(42,43)}$. The factors regulating the differences in $\beta$-casein phosphorylation between mothers and over the course of lactation are unclear. Genetic factors may account for some of the inter-individual variation, with many different polymorphisms of both $\beta$-casein and casein kinase genes reported ${ }^{(44)}$. It is also possible that hormonal differences between term and preterm mothers and within mothers over the course of lactation may account for the observed differences in casein phosphorylation. Casein kinase, for example, has been found to respond to a number of different hormonal signals ${ }^{(45)}$. The changing hormonal milieu throughout lactation may have an effect on casein kinase activity and, consequently, on the extent of $\beta$-casein phosphorylation.

The biological significance of this variation in casein phosphorylation patterns is unknown. Certainly, the formation of casein micelles, structures enabling the transmission of otherwise insoluble concentrations of $\mathrm{Ca}$ and phosphate to the infant, is dependent on the phosphorylation of both $\beta$-casein and $\alpha_{\mathrm{s} 1}$-casein ${ }^{(11)}$. In addition to the transport of $\mathrm{Ca}$ and phosphate, another important function of the casein micelle is the curding or coagulation it undergoes in the infant stomach when acted upon by the enzyme chymosin. Curding results in a delay of the entry of milk constituents into the small intestine, thereby improving digestibility and facilitating the spacing of feeding intervals ${ }^{(46)}$. It is not clear whether the differing casein phosphorylation patterns affect either the structure of the casein micelle and its ability to transport $\mathrm{Ca}$ and phosphate or the behaviour of casein micelles in the infant stomach. However, the differing phosphorylation pattern of $\beta$-casein would certainly have an effect on the nature of the casein peptides produced during digestion. Casein phosphopeptides perform a large range of bioactive functions in the infant, including increasing mineral absorption, immunomodulation and opioid roles ${ }^{(47,48)}$. It is possible that the differing patterns of $\beta$-casein phosphorylation, in both between term and preterm mothers, and over the course of lactation, exert a biological effect within breastfed infants through the production of different sets of casein peptides.

A limitation of the present study is that data regarding the volume of milk produced by each mother were unavailable. This is unfortunate from a nutritional perspective, as it prevents any analysis of the total amount of each protein received by the infant. Furthermore, it precludes an analysis of the relationship between protein concentration and milk production. There are conflicting reports in the literature regarding this relationship, particularly with regard to differences between term and preterm milk ${ }^{(4,5)}$, and further studies are required. In addition, it would be interesting to investigate whether the PTM differences that we observed in the preterm mothers are related to levels of milk production, as this may provide insight into the physiological mechanisms responsible for the observed variation.

\section{Conclusions}

The concentration of the major proteins in human milk was found to decrease over the first month of lactation and to be similar in both term and preterm milk. With the exception of the glycoproteins, tenascin and serum albumin, the carbohydrate content of the proteins did not change over this time period and was also similar in term and preterm milk. The phosphorylation of $\beta$-casein was found to differ between term and preterm milk and to vary widely amongst preterm mothers. Further investigation is required to determine whether these modifications have an effect on protein function and are of clinical importance to preterm infants.

\section{Acknowledgements}

The present study was funded by an unrestricted grant from Medela AG (Switzerland) to the University of Western Australia. C. E. M. was supported by a scholarship from the Western Australian Women's Service Guild (2009-11) and an

\footnotetext{
can micelles, structures enabling the transmission of
} 
Australian Postgraduate Award (2009-11). B. T. H. contributed to the sample collection and reviewed the manuscript. Y. S. C., P. G. A. and P. E. H. critically reviewed the manuscript. C. E. M. was involved in the study design, performed the laboratory work, data analysis and wrote the initial manuscript. None of the authors had a financial or personal conflict of interest regarding the content of this manuscript.

\section{References}

1. Schanler R (2007) Mother's own milk, donor human milk, and preterm formulas in the feeding of extremely premature infants. J Pediatr Gastroenterol Nutr 45, S175-S177.

2. Lonnerdal B (2004) Human milk proteins: key components for the biological activity of human milk. Adv $\operatorname{Exp}$ Med Biol 554, 11-25.

3. de Halleux V, Close A, Stalport S, et al. (2007) Advantages of individualised fortification of human milk for preterm infants. Arch Pediatr 14, S5-S10.

4. Atkinson SA (1995) Effects of gestational stage at delivery on human milk components. In Handbook of Milk Composition, pp. 222-237 [RG Jensen, editor]. San Diego, CA: Academic Press.

5. Bauer J \& Gerss J (2011) Longitudinal analysis of macronutrients and minerals in human milk produced by mothers of preterm infants. Clin Nutr 30, 215-220.

6. Grosse SJ, Geller J \& Tomarelli RM (1981) Composition of breast milk from mothers of preterm infants. Pediatrics $\mathbf{6 8}$, 490-493.

7. Schroten H, Hanisch FG, Plogmann R, et al. (1992) Inhibition of adhesion of S-fimbriated Escherichia coli to buccal epithelial cells by human milk fat globule membrane components: a novel aspect of the protective function of mucins in the nonimmunoglobulin fraction. Infect Immun 60, 2893-2899.

8. Yolken RH, Peterson JA, Vonderfescht SL, et al. (1992) Human milk mucin inhibits rotavirus replication and prevents experimental gastroenteritis. J Clin Invest 90, 1984-1991.

9. van Veen H, Geerts M, van Berkel P, et al. (2004) The role of $\mathrm{N}$-linked glycosylation in the protection of human and bovine lactoferrin against tryptic proteolysis. Eur J Biochem 27, 678-684.

10. Barboza M, Pinzon J, Wickramasinghe S, et al. (2012) Glycosylation of human milk lactoferrin exhibits dynamic changes during early lactation enhancing its role in pathogenic bacteria-host interactions. Mol Cell Proteomics 11 M111.015248.

11. Qi PX (2007) Studies of casein micelle structure: the past and the present. Lait $\mathbf{8 7}, 363-383$.

12. Biohallab S \& Bougle D (2004) Biopeptides of milk: caseinophosphopeptides and mineral bioavailability. Reprod Nutr Dev 44, 493-498.

13. Kunz C \& Lonnerdal B (1989) Human milk proteins: separation of whey proteins and their analysis by polyacrylamide gel electrophoresis, fast protein liquid chromatography (FPLC) gel filtration, and anion-exchange chromatography. Am J Clin Nutr 49, 464-470.

14. Mitoulas L, Kent J, Cox D, et al. (2002) Variation in fat, lactose and protein in human milk over $24 \mathrm{~h}$ and throughout the first year of lactation. BrJ Nutr $\mathbf{8 8}, 29-37$.

15. Laemmli U (1970) Cleavage of structural proteins during the assembly of the head of bacteriophage T4. Nature $\mathbf{2 2 7}$, 680-685.
16. Molinari CE, Casadio YS, Arthur PG, et al. (2011) The effect of storage at $25^{\circ} \mathrm{C}$ on proteins in human milk. Int Dairy $J$ 21, 286-293.

17. Kinoshita E, Kinoshita-Kikuta E, Matsubara M, et al. (2009) Two-dimensional phosphate-affinity gel electrophoresis for the analysis of phosphoprotein isotypes. Electrophoresis 30, 550-559.

18. Shevchenko A, Tomas H, Havlis J, et al. (2007) In-gel digestion for mass spectrometric characterisation of proteins and proteomes. Nat Protoc 1, 2856-2860.

19. $\mathrm{R}$ Development Core Team (2008) $R$ : A Language and Environment for Statistical Computing. Vienna: R Foundation for Statistical Computing.

20. Pinheiro J, Bates D, DebRoy S, et al. (2008) nlme: Linear and Nonlinear Mixed Effects Models. R package version 3.1-89.

21. Hothorn T, Bretz F \& Westfall P (2008) Simultaneous inference in general parametric models. Biometric J 50, 346-363.

22. Montagne $\mathrm{P}$, Cuilliere ML, Mole C, et al. (1999) Immunological and nutritional composition of human milk in relation to prematurity and mothers' parity during the first 2 weeks of lactation. J Pediatr Gastroenterol Nutr 29, 75-80.

23. Lonnerdal B (2003) Nutritional and physiologic significance of human milk proteins. Am J Clin Nutr 77, 1537S-11543.

24. Ziegler EE (2001) Breast-milk fortification. Acta Paediatr 90, $720-723$.

25. Arslanoglu S, Moro G \& Ziegler E (2006) Adjustable fortification of human milk fed to preterm infants; does it make a difference? J Perinatol 26, 614-621.

26. Brines RD \& Brock JH (1983) The effect of trypsin and chymotrypsin on the in vitro antimicrobial and iron-binding properties of lactoferrin in human milk and bovine colostrum: unusual resistance of human apolactoferrin to proteolytic digestion. Biochim Biophys Acta 759, 229-235.

27. Newburg D (1996) Oligosaccharides and glycoconjugates in human milk: their role in host defense. J Mammary Gland Biol Neoplasia 1, 271-283.

28. Froehlich JW, Dodds ED, Barboza M, et al. (2010) Glycoprotein expression in human milk during lactation. J Agric Food Chem 58, 6440-6448.

29. Landberg E, Huang Y, Stromqvist M, et al. (2000) Changes in glycosylation of human bile-salt-stimulated lipase during lactation. Arch Biochem Biophys 377, 246-254.

30. Kunz C \& Lonnerdal B (1990) Human-milk proteins: analysis of casein and casein subunits by anion exchange chromatography, gel electrophoresis, and specific staining methods. Am J Clin Nutr 51, 37-46.

31. Chaturvedi P, Warren CD, Altaye M, et al. (2001) Fucosylated human milk oligosaccharides vary between individuals and over the course of lactation. Glycobiology 11, 365-372.

32. Hsia H \& Schwarzbauer J (2005) Meet the tenascins: multifunctional and mysterious. J Biol Chem 280, 26641-26644.

33. Jones PL, Boudreau N, Myers CA, et al. (1995) Tenascin-C inhibits extracellular matrix-dependent gene expression in mammary epithelial cells. Localization of active regions using recombinant tenascin fragments. J Cell Sci $\mathbf{1 0 8}$, 519-527.

34. Cella N, Chiquet-Ehrismann R \& Hynes NE (2000) Lactogenic hormones and tenascin-C regulate $\mathrm{C} / \mathrm{EBP} \alpha$ and $\beta$-casein in mammary epithelial cells. $J$ Cell Biochem 76, 394-403.

35. Monks J \& Neville MC (2004) Albumin transcytosis across the epithelium of the lactating mouse mammary gland. J Physiol 560, 267-280.

36. Lonnerdal B, Atkinson S, Robert GJ, et al. (1995) Human milk proteins. In Handbook of Milk Composition, pp. 351-368 [RG Jensen, editor]. San Diego, CA: Academic Press. 
37. van Boekel MAM, van den Bergh PJPC \& Hoenders HJ (1992) Glycation of human serum albumin: inhibition by Diclofenac. Biochim Biophys Acta 1120, 201-204.

38. Oettl K \& Stauber RE (2007) Physiological and pathological changes in the redox state of human serum albumin critically influence its binding properties. Br J Pharmacol 151, $580-590$.

39. Joshi S, Mehendale S, Dangat K, et al. (2008) High maternal plasma antioxidant concentrations associated with preterm delivery. Ann Nutr Metab 53, 276-282.

40. Quiles JL, Ochoa JJ, Ramirez-Tortosa MC, et al. (2006) Coenzyme $\mathrm{Q}$ concentration and total antioxidant capacity of human milk at different stages of lactation in mothers of preterm and full-term infants. Free Radic Res 40, 199-206.

41. Nakajou K, Watanabe H, Kragh-Hansen U, et al. (2003) The effect of glycation on the structure, function and biological fate of human serum albumin as revealed by recombinant mutants. Biochim Biophys Acta 1623, 88-97.

42. Poth A, Deeth H, Alewood P, et al. (2008) Analysis of the human casein phosphoproteome by $2 \mathrm{D}$ electrophoresis and MALDI-TOF/TOF MS reveals new phosphoforms. J Proteome Res 7, 5017-5027.

43. Kunz C \& Lonnerdal B (1995) Casein and casein subunits in preterm milk, colostrum, and mature human milk. J Pediatr Gastroenterol Nutr 10, 454-461.

44. Greenberg R, Groves ML \& Dower HJ (1984) Human betacasein. Amino acid sequence and identification of phosphorylation sites. J Biol Chem 259, 5132-5138.

45. Allende JE \& Allende CC (1995) Protein kinases. 4. Protein kinase CK2: an enzyme with multiple substrates and a puzzling regulation. FASEB J 9, 313-323.

46. Miller MJS, Witherly SA \& Clark DA (1990) Casein: a milk protein with diverse biologic consequences. Proc Soc Exp Biol Med 195, 143-159.

47. Meisel H \& Bockelmann W (1999) Bioactive peptides encrypted in milk proteins: proteolytic activation and tropho-functional properties. Antonie van Leeuwenhoek 76, 207-215.

48. Ferraretto A, Signorile A, Gravaghi C, et al. (2001) Casein phosphopeptides influence calcium uptake by cultured human intestinal HT-29 tumor cells. J Nutr 131, 1655-1661. 